Columbia Law School

Scholarship Archive

\title{
Lessons and Opportunities for Negotiation Teachers Following the Covid-19 Pandemic
}

Ana Lenard

Columbia Law School

Follow this and additional works at: https://scholarship.law.columbia.edu/llm_essays_theses

Part of the Legal Education Commons

\section{Repository Citation}

Lenard, Ana, "Lessons and Opportunities for Negotiation Teachers Following the Covid-19 Pandemic" (2021). LL.M. Essays \& Theses. 3.

https://scholarship.law.columbia.edu/IIm_essays_theses/3

This Essay is brought to you for free and open access by the Student Scholarship at Scholarship Archive. It has been accepted for inclusion in LL.M. Essays \& Theses by an authorized administrator of Scholarship Archive. For more information, please contact scholarshiparchive@law.columbia.edu. 
Lessons and opportunities for negotiation teachers following the Covid-19 pandemic

\section{Ana Lenard}

Submitted in partial fulfillment of the requirements

for the degree of Master of Laws in the

School of Law

Columbia University 


\section{TABLE OF CONTENTS}

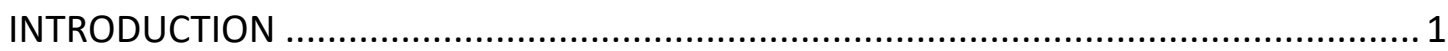

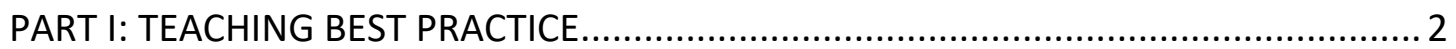

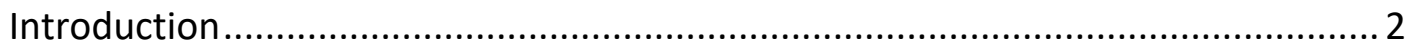

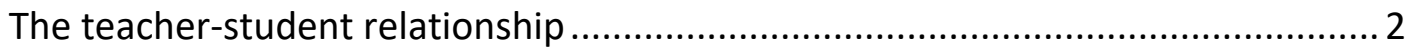

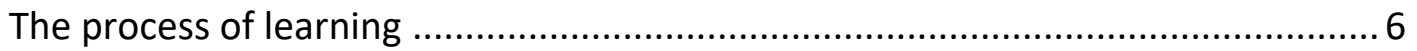

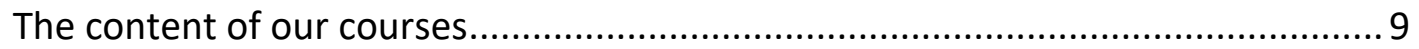

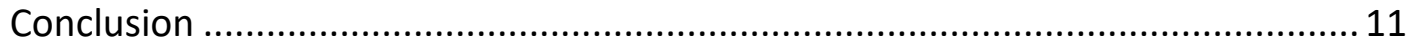

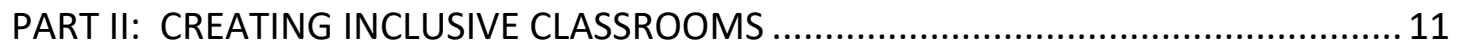

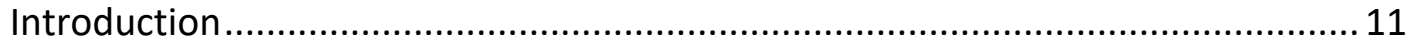

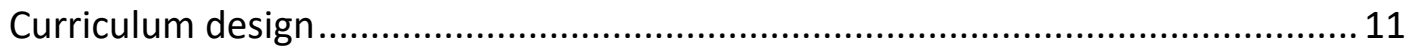

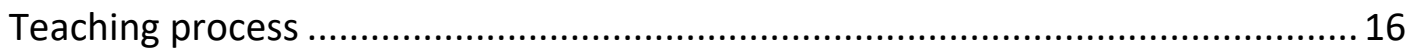

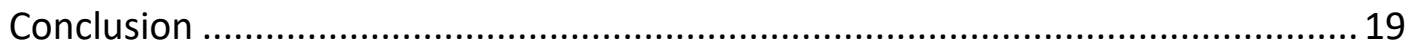

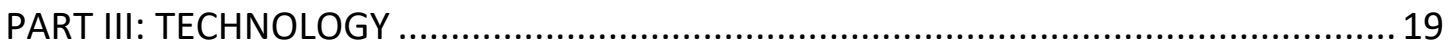

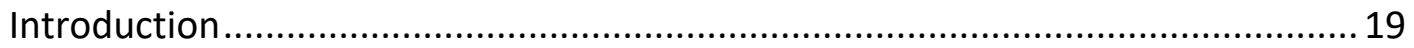

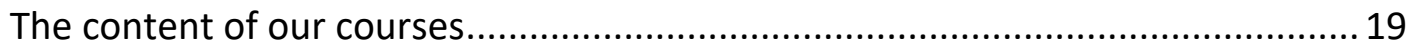

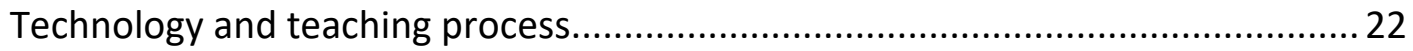

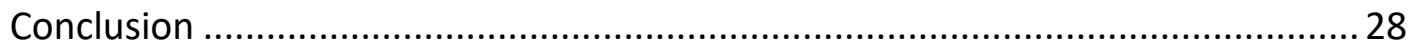

PART IV: EQUIPPING OUR STUDENTS TO MEET THE DEMANDS OF THE MODERN

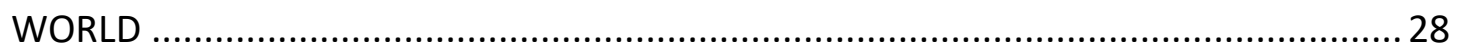

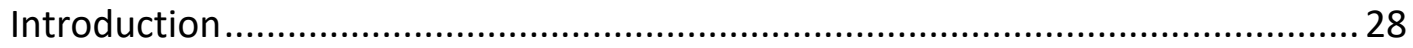

Taking our changed world into account in our teaching ................................... 28

Answering the call to provide capacious legal education..................................... 31

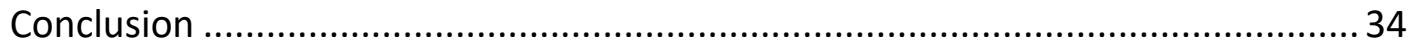

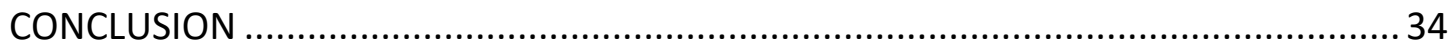

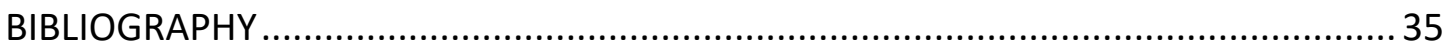




\section{Lessons and opportunities for negotiation teachers following the Covid-19 pandemic}

\section{INTRODUCTION}

Anxious. Uncomfortable. Cautiously optimistic. Excited. Exhausted. Converted.

These words describe parts of the arc I experienced when teaching negotiation online between March and June of $2020 .{ }^{1}$ I have also had the opportunity to examine the topic of online teaching from two other angles: between August and September of 2020 I taught a portion of one of my courses online again (with the benefit of having done it once before); and from September 2020 until April 2021 I was a law master's student (including in an advanced negotiation course), studying remotely from Auckland, New Zealand. With my online teaching and learning drawing to a close, this is the opportune moment to reflect on my experiences, ground them in current pedagogical research, and offer my thoughts on takeaways for negotiation teachers.

A number of scholars have created useful online teaching resources. ${ }^{2}$ I do not wish to duplicate that work. The aim of this paper is to distil lessons and opportunities

1 I taught Negotiation, Mediation and Dispute Resolution (52 students) and I also taught Legal Ethics (200+ students) at Te Whare Wananga o Tāmaki Makaurau, Te Wāhanga Ture (the University of Auckland Faculty of Law). These are both senior undergraduate law papers, and Legal Ethics is a compulsory course for students seeking admission to the bar in Aotearoa New Zealand.

2 See, e.g., the work of Noam Ebner, https://papers.ssrn.com/sol3/cf dev/AbsByAuth.cfm?per id=425153 (last visited Apr. 23, 2021); Ong Ee Ing, The year of COVID-19: Personal reflections on how traditional pedagogy can be informed by online teaching methods (aka how I changed my mind about online teaching), in Law and COVID-19 177 (Aurelio Gurrea-Martínez, Mark Findlay and Goh Yihan, eds., 2020); Chrysi Rapanta et al., Online University Teaching During and After the Covid-19 Crisis: Refocusing Teacher Presence and Learning Activity, 2 Postdigital Science and Education 923 (2020); Best Practices for Online Teaching, Mitchell Hamline School of Law (May. 21, 2020), https://mitchellhamline.edu/dispute-resolution-institute/2020/05/21/presentation-mitchellhamline-best-practices-for-online-teaching/; Best Practices: Online Pedagogy, Harvard University, https://teachremotely.harvard.edu/best-practices (last visited Apr. 23, 2021). 
for negotiation teaching arising from the pandemic. Rarely do we get an opportunity like this - when regular life for many people grinds to a halt - to reconsider the foundations of our world. The pandemic is a chance to create a 'new normal' that serves our students better. ${ }^{3}$

In Part I of this paper I set the stage for how we can assess the utility of lessons and opportunities arising from the pandemic by outlining teaching best practice. I then discuss lessons and opportunities across three themes: creating an inclusive classroom (Part II); technology (Part III); and equipping our students to be able to meet the demands of the modern world (Part IV).

\section{PART I: TEACHING BEST PRACTICE}

\section{Introduction}

In this part I set out pedagogical best practice to offer us a standard by which we can assess the value of lessons and opportunities flowing from the pandemic. I discuss the teacher-student relationship, deep learning, and the content of curricula, in turn.

\section{The teacher-student relationship}

Teaching is more than a job or a career ... [it involves] devotion to our students, to our profession, and to the craft of teaching ... [i]n teaching with devotion, we remain open to our students' hearts and minds, to their feelings as well as their thinking. ${ }^{4}$

The teacher-student relationship is a sacred bond that carries with it the privilege and responsibility of guiding people in their learning and growth. Our understanding of

3 Dionne Brand, On narrative, reckoning and the calculus of living and dying, Toronto Star (Jul. 5, 2020), https://www.thestar.com/entertainment/books/2020/07/04/dionne-brand-on-narrativereckoning-and-the-calculus-of-living-and-dying.html.

4 Robert DiYanni and Anton Borst, The Craft of College Teaching: A Practical Guide xi (2020). 
how this can most effectively be done has shifted considerably in the last few decades towards "transformational teaching" which is "creating dynamic relationships between teachers, students and a shared body of knowledge to promote student learning and personal growth". ${ }^{5}$ We are "intellectual coaches" ${ }^{6}$ to our students and we collaborate in the classroom in order to achieve mastery of knowledge:

In contrast with traditional lecturing, which involves a largely unidirectional transfer of information from an instructor to students, transformational teaching involves conceptualizing teachers as change agents who lead students in the process of collaborating with one another and with their instructor to develop as learners and as people. $^{7}$

A transformational teacher will facilitate students' attainment and mastery of knowledge; support the development of strategies for learning; and promote positive attitudes, values and beliefs about learning. ${ }^{8}$ What transformational teaching looks like is open ended, but can be thought of as comprising a shared vision for the course; providing opportunities for mastery; encouraging students and challenging them intellectually; ${ }^{9}$ providing individual attention and personalised feedback ${ }^{10}$ (and seeking feedback from students and course correcting); ${ }^{11}$ taking teaching beyond the

5 George M. Slavich and Philip G. Zimbardo, Transformational Teaching: Theoretical Underpinnings, Basic Principles, and Core Methods, 24 Educational Psychology Review 569, 576 (2012).

Id. at 576.

7 Id. at 577.

Id. at 581-585.

9 As well as being engaging (Liam Elphick, Adapting Law Lectures to Maximise Student Engagement: Is it Time to 'Transform'?, 28 Legal Education Review 1, 13 (2018)), rapport is important for building trust (Robert Fisher, William Ury and Bruce Patton, Getting to Yes 40 (2011)) and liking is important for persuasion (Robert Cialdini, Influence: The Psychology of Persuasion chapter 5 (2006)).

10 Feedback is important for students' long-term learning: Bobbi McAdoo and Melissa Manwaring, Teaching for Implementation: Designing Negotiation Curricula to Maximize Long-Term Learning, 25(2) Negotiation Journal 195, 212 (2009). Consistent with the theory of transformational teaching, feedback is most useful when it homes in on people's strengths rather than focusing on what we personally do not like: Marcus Buckingham and Ashley Goodall, The Feedback Fallacy, Harvard Business Review (Mar-Apr. 2019), https://hbr.org/2019/03/the-feedback-fallacy.

11 Knowing that feedback can improve their learning experiences is a satisfying outcome for 
classroom walls through experiential learning; providing opportunities for reflection before and after learning takes place; $;^{12}$ and understanding that people are not fixed and that they are capable of growth. ${ }^{13}$

At the heart of transformational teaching is deep respect and care for our students, which naturally includes the need to create safe and inclusive learning spaces. ${ }^{14}$ Others have persuasively articulated why inclusion and integration matter, so I mention only briefly the sources of these arguments: human rights (the law requires it); ${ }^{15}$ professional responsibility and competency (we are obliged to serve our

students: Vicci Y.J. Lau, How to Encourage Student Voice: Obtaining Effective Feedback from Law Students in Course Evaluation, 29 Legal Education Review 1, 2 and 4 (2019). On pre-course surveys, see Denise Harshbarger, Universal Design for Learning (UDL): A beginner's guide for online higher education instructors, 4 Journal of Online Higher Education 51, 53 (2020). Slavich and Zimbardo, supra note 5 at 585-596.

13 Carol Dweck, Mindset (2007).

14 'We need to figure out how to welcome [students'] range of differences and create a space where diverse perspectives, ideas, and values can be accommodated and validated. This openness speaks to a fundamental principle of teaching: the importance of creating an environment in which all students feel included and are confident in presenting their ideas and conveying their feelings, and in which all voices can be heard": DiYanni and Borst, supra note 4 at 4, 36.

15 See, e.g., Education and inclusion should be human rights priorities, UN Assembly hears, UN News (Nov. 1, 2019), https://news.un.org/en/story/2019/11/1050431; Lisa Waddington and Carly Toepke, Moving Towards Inclusive Education as a Human Right: An analysis of international legal obligations to implement inclusive education in law and policy (2014); Inspiring National Indigenous Education for Aotearoa New Zealand's Bachelor of Laws Degree (2020). 
students as best as we $\operatorname{can}^{16}$ and are certainly obliged not to harm them, ${ }^{17}$ and negotiation, at its core, is about peaceful communication and co-existence); ${ }^{18}$ economics (diversity and inclusion generate stronger businesses and economies); ${ }^{19}$ and spirituality (a capacious view of personhood means honouring the need we all have to survive and thrive). ${ }^{20}$ Some of these arguments are framed narrowly ("It's the right thing to do" or "We have to"), but inclusion is at its best when it comes from an abundance mindset: together we are better when we are integrated, and the whole is greater than the sum of its parts. ${ }^{21}$ I discuss creating inclusive classrooms in Part II.

16 Slavich and Zimbardo, supra note 5 at 571: "instructors should shape course curricula and content based on students' needs, abilities, interests, and learning styles" and 587: "This notion of collective influence and responsibility for individuals' personal successes is inherent in social cognitive theory and transformational leadership ... and is a defining characteristic of transformational teaching." Research has shown that failing to understand and accommodate for indigenous' students' needs, for example, leads to the suspension or termination of studies when indigenous students face family or health crises or when they fail to receive much needed support: Melanie Schwartz, Retaining Our Best: Imposter Syndrome, Cultural Safety, Complex Lives and Indigenous Student Experiences of Law School, 28 Legal Education Review 1, 6 (2018). Creating a culturally safe space (the provision of a service for people within their cultural norms and values) is therefore important, particularly for students from a traditionally dispossessed group: at 10. Equally, we are obliged to equip our students with the literacy they need to live in our world - "racial literacy is a matter of literacy as such": Kendall Thomas, Professor at Columbia Law School, Presentation at the University of Wisconsin Law Review Symposium: Critical Race Theory - Origins, Permutations, and Current Queries (Oct. 22, 2020).

17 "Feelings of alienation among Indigenous students in tertiary education are often further compounded for students studying law because of the role of the law in producing, entrenching and perpetuating disadvantage for [indigenous people]": Schwartz, supra note 16 at 9.

18 See, e.g., the UN Convention on International Settlement Agreements Resulting from Mediation, preamble (2019): "Recognizing the value of mediation as a method of amicably settling disputes arising in the context of international commercial relations". See also Fisher, Ury and Patton, supra note 9 at xi, where the authors remind us that conflict is useful for democracy, and "the challenge is not to eliminate conflict but to transform it [and] change the way we deal with our differences - from destructive, adversarial battling to hard-headed, side-by-side problem-solving".

19 See, e.g., Diversity wins: How inclusion matters, McKinsey \& Company (May. 19, 2020), https://www.mckinsey.com/featured-insights/diversity-and-inclusion/diversity-wins-howinclusion-matters; Vijay Eswaran, The business case for diversity in the workplace is now overwhelming, World Economic Forum (Apr. 29, 2019), https://www.weforum.org/agenda/2019/04/business-case-for-diversity-in-the-workplace/. See, e.g., Eva Feder Kittay, When Caring Is Just and Justice Is Caring: Justice and Menta Retardation, 13(3) Public Culture 557 (2001).

21 See, e.g., Ambelin Kwaymullina, Teaching for the 21st Century: Indigenising the law curriculum at 


\section{The process of learning}

Long-term memory retention takes place when learning is active and effortful ${ }^{22}$ and when new information links to students' existing experiences and knowledge in some way. ${ }^{23}$ That is why activities like role plays and role play design, simulations, ${ }^{24}$ fish bowls, ${ }^{25}$ annotated reading and blogs, ${ }^{26}$ adventure learning ${ }^{27}$ and experiential learning ${ }^{28}$ are preferable to receiving information passively from readings and lecturing. Helpfully, active learning enhances dynamism in the classroom, which is important for student engagement during lectures. ${ }^{29}$ But not all active learning activities are created equal. There is evidence that role play design is a more effective form of learning than role play participation. ${ }^{30}$ Moreover, multi-stage role plays, or

UWA, 29 Legal Education Review 1, 8-10 (2019).

22 Peter C. Brown, Henry L. Roediger III and Mark A. McDaniel, Make it stick: The science of successful learning 2 (2014).

23 Id. at 5 . This is particularly so because our students come to our courses having negotiated all their lives and they bring particular skills and approaches: Bruce Patton, The Deceptive Simplicity of Teaching Negotiation: Reflections on Thirty Years of the Negotiation Workshop, 25(4) Negotiation Journal 481, 491 (2009).

24 Multi-stage role plays: Arvid Bell and Taylor Valley, The Art of Negotiation Exercise Design: Five Basic Principles to Produce Powerful Learning Experiences, Negotiation Journal 57, 63 (2020).

25 Watching and analysing a negotiation: Robert Bordone and Chad Carr, Critical Decisions in Negotiation: A New Video Resource for Teaching Negotiation, 29(4) Negotiation Journal 463, 464 (2013).

26 It will be important to encourage participation with feedback or coaching, or even enlisting students as coaches: DiYanni and Borst, supra note 4 at 90 . On the topic of class blogs, see lan Macduff, Using Blogs in Teaching Negotiation: A Technical and Intercultural Postscript, 28(2) Negotiation Journal 201 (2012). We use a class blog in the negotiation course that I teach. It is a creative way to get students to collaborate in generating knowledge, however, design is crucial particularly how the knowledge that is gathered can be shared with the rest of the class and how to improve the quality of student contributions.

27 Learning activities with real-world implications e.g., role playing in the real world, negotiating on one's behalf, or applying a concept outside of class: see Christopher Honeyman, James Coben and Giuseppe De Palo (eds), Venturing Beyond the Classroom (2010), particularly chapters 7 and 8 which offer tips on effective design and chapter 9 for activity ideas. Micro-skills are ripe subjects for adventure learning assignments: Patton, supra note 23 at 489.

28 On how to assess whether an experiential learning component is a valuable addition to the curriculum, see DiYanni and Borst, supra note 4 at 152.

29 See, e.g., Elphick, supra note 9 at 13.

30 Research shows longer-term knowledge retention and higher levels of student motivation: Daniel Druckman and Noam Ebner, Discovery Learning in Management Education: Design and Case 
simulations, offer a more realistic picture of how students would negotiate in the real world compared to simple role plays. ${ }^{31}$ One of the difficulties teachers sometimes experience is striking a balance between active learning and imparting necessary knowledge. Substantive instruction can be built into active learning activities through preparatory and background readings. Another approach is 'flipping' the lecture, which involves delivering recorded instructional material in advance of class and then conducting active learning exercises during class time. ${ }^{32}$

Unfortunately, some of the things that are most productive for learning also feel the most uncomfortable for learners and can cause frustration. Massed practice feels good but is unproductive. ${ }^{33}$ Tasks need to be interleaved and spaced out in order for the skill that is being practiced to stick. ${ }^{34}$ Retrieval - recalling knowledge from memory - is more effective than simple and enjoyable tasks like re-reading material, and is most effective when spaced out to enable some forgetting to take place. ${ }^{35}$ Testing and quizzes, ${ }^{36}$ especially with feedback, are a very effective way to practice

Analysis, 42(3) Journal of Management Education 347, 355 (2018). See also Patrick GermainThomas et al., Collaborative Role-Play Design: Teaching Negotiation through a Novel StudentBusiness Partnership, Negotiation Journal 387, 390, 395-396, 398 (2019).

31 Bell and Valley, supra note 24 at 62.

32 See, e.g., Felix E. Mezzanotte, Do (Underperforming) Students Benefit from a Flipped Lecture? Evidence from Business Students Studying Company Law, 28 Legal Education Review 1 (2018), concluding in a flipped lecture experiment that low GPA students enjoyed flipped lectures more and performed better on assessments of the content of those lectures.

33 Brown, Roediger and McDaniel, supra note 22 at 3.

34 Id. at 3. Sleep plays an important role in memory formation, which is why spacing practice out across a few days can be helpful: 63. Interleaving tasks also seems to improve one's ability to decide which skill to apply to different problems later on (which is particularly important in fluid and unpredictable environments like negotiations): 64 .

35 Id. at 3 and 32.

36 Ing, supra note 2 at 182 . Learning management systems might contain a quiz function but there are also other programs, like Quizlet, that can be used: Diane Moffat and Kenneth Mark Wallin, An Examination of Online Course Design, 2 Journal of Online Higher Education 1, 8 (2018). 
retrieval, despite being despised by students. ${ }^{37}$ Attempting to solve a problem before being taught the solution is also effective for long-term learning, even if error laden. ${ }^{38}$ Reflective journals can strike a good balance because they are, in my view, a more enjoyable form of assessment, but can also be designed to connect to students' contexts and existing knowledge and to include memory retrieval. ${ }^{39}$ The tension between enjoyable (but less effective) activities and unenjoyable (but effective) activities can also be dealt with by explaining the science of learning to our students. ${ }^{40}$

There are many activities that could be included in a negotiation course in order to support deep learning. Determining whether exercises are useful involves having a clear purpose and format, testing the activity and debriefing. ${ }^{41}$ Resources must also be considered in terms of staff available to administer the activity, meeting rooms, computers and other materials. We also have to consider how much time we can realistically dedicate to marking various components of a practical course and whether technology, like self-marking quizzes, can assist. ${ }^{42}$

37 DiYanni and Borst, supra note 4 at 72 and Brown, Roediger and McDaniel, supra note 22 at 4, 39. Testing that requires short answers rather than multi-choice answers seems to be even more effective, although multi-choice tests are better than no testing: 40. Brown, Roediger and McDaniel, supra note 22 at 4.

39 Id. at 26.

40 Id. at 225. In addition to concerns that end of course evaluations perpetuate various biases and fail to accurately assess teacher competence, they can supress unpopular pedagogy that produces better student results: Warwick Fisher et al., Student Evaluations: Pedagogical Tools or Weapons of Choice?, 30 Legal Education Review 1, 25-28 (2020).

41 Bell and Valley, supra note 24 at 57 . Surveys can be useful for testing whether the activity achieved its purpose, whether instructions were clear, and how the exercise might be improved in future: 66 . Debriefing, both plenary and individual reflection, should be focused with targeted questions and should relate back to the purpose of the exercise: 69.

42 Id. at 65. 


\section{The content of our courses}

Best practice means teaching our students what they need in order to navigate the modern world. ${ }^{43}$ While an uncontroversial point, teaching students what they actually need to learn is easier said than done. I can think of at least two reasons for this.

The first is that both the attainment of skills and long-term knowledge retention are best done through active learning strategies. Active learning strategies take more time and effort than knowledge transfer through lecturing. Time is at a premium for full-time faculty, who have numerous teaching, research and writing obligations, and administrative duties. Time is also at a premium for clinical and adjunct faculty, who are busy practitioners with other work to do. There is therefore a tension between the amount of time that is available and the time commitment required for transformational teaching.

The second issue is that we do not exist in the same world as our students, who are facing a different job market. It might therefore be difficult for us to assess precisely what skills and knowledge they need in order succeed after university. ${ }^{44}$ This issue is compounded if we have a narrow area of expertise, like litigation settlement, when negotiation is a discipline of extremely broad application.

Addressing these concerns in turn, we need our institutions to help us create the time to properly advance transformational teaching goals, including by providing us with adequate pedagogical training. We also need ways of finding out what our

43 See Carrie Menkel-Meadow, Crisis in Legal Education or the Other Things Law Students Should Be Learning and Doing, 45 McGeorge L. Rev. 133, 133-134 (2013).

44 See, e.g., Noam Ebner and Joan Stearns Johnsen, Mismatches between mediation teaching and practice: A first community conversation, 1 ACResolution 16 (2019). 
students need to learn in order to be able to navigate the modern world. Fortunately, negotiation courses are often ahead of the curve in terms of teaching useful skills. Still, there is room for improvement, which I discuss more in Part IV below.

One pre-pandemic development that met a clear modern demand was the introduction of self-awareness practices like mindfulness. In addition to supporting wellbeing, focus and productivity, ${ }^{45}$ mindfulness and awareness practices are critical for being a successful negotiator. ${ }^{46}$ Good negotiators are able to respond rather than react and can exercise choices with intentionality. In addition to the evidence that negotiation courses can generally improve law student wellbeing because of the relational skills they impart, ${ }^{47}$ self-awareness components can further improve student wellbeing by contributing to reduced stress, depression and anxiety, and helping students let go of limiting beliefs. ${ }^{48}$ I discuss in Part IV how the pandemic offers lessons and opportunities for us to deepen our teaching of these tools.

45 Daphne M. Davis and Jeffrey A. Hayes, What are the benefits of mindfulness, American Psychological Association (Jul-Aug. 2012), https://www.apa.org/monitor/2012/07-08/ce-corner.

46 See, e.g., William Ury, Getting Past No: Negotiating Your Way From Confrontation to Cooperation 36-51 (1993) (discussing going to the 'balcony'); Michael Wheeler, The Art of Negotiation: How to Improvise Agreement in a Chaotic World 90 (2013); Leonard Riskin and Rachel Wohl, Mindfulness in the Heat of Conflict: Taking Stock, 20 Harvard Negotiation Law Review 121 (2015); Darshan Brach, A Logic for the Magic of Mindful Negotiation, 24(1) Negotiation Journal 25 (2008).

47 James Duffy and Rachael Field, Why ADR must be a mandatory subject in the law degree: A cheat sheet for the willing and a primer for the non-believer, 25(1) Australasian Dispute Resolution Journal 3, 11 (2014).

48 Laurie Squillaci, Mindfulness as a Tool for Student Achievement in Higher Education: Insights, Benefits, and Exercises, 2 Journal of Online Higher Education 1, 3, 5 (2018). 


\section{Conclusion}

In this part I have set the stage for how we might assess the value of lessons and opportunities arising from the pandemic by summarising modern thinking about the teacher-student relationship, the process of learning, and the content of curricula.

\section{PART II: CREATING INCLUSIVE CLASSROOMS}

\section{Introduction}

The post-pandemic recovery phase is the opportune moment to do our part as negotiation teachers in answering the call to create a "new normal" that is more equitable. ${ }^{49}$ I have outlined the arguments as to why creating inclusive and integrated classrooms is crucial for transformational teaching and is therefore a core teaching competency. In this part, I discuss how we can do that work.

\section{Curriculum design}

When we teach alternative dispute resolution (ADR) history, as many of us do, from which angle do we take it? ADR systems can and do act in service of White privilege, patriarchy and ableism. ${ }^{50} \mathrm{ADR}$ as a response to the problems with traditional litigation presupposes access to the courts in the first place, and the attainment of any kind of meaningful justice in that forum. ${ }^{51}$ Although ADR systems can be transformative for

49 See, e.g., WHO urges countries to build a fairer, healthier world post-Covid-19, World Health Organization (Apr. 6, 2021), https://www.who.int/news/item/06-04-2021-who-urges-countriesto-build-a-fairer-healthier-world-post-covid-19; and Brand, supra note 3. See also Great Reset, Time, https://time.com/collection/great-reset/ (last visited Apr. 24, 2021) and The Great Reset, World Economic Forum, https://www.weforum.org/great-reset/ (last visited Apr. 24, 2021).

50 Richard Delgado et al., Fairness and Formality: Minimizing the Risk of Prejudice in Alternative Dispute Resolution, 6 Wis. L. Rev. 1359 (1985).

51 Charles Mills, The Racial Contract, Introduction (1997); Andrew Mamo, Against Resolution: Dialogue, Demonstration, and Dispute Resolution, Ohio State Journal on Dispute Resolution (forthcoming) at 6; Patricia Williams, Alchemical Notes: Reconstructing Ideals from Deconstructed 
people irrespective of their social positioning, the nature of the ADR system and the needs and goals it serves will ultimately determine whether it is. We should therefore ask ourselves about whether we teach a complete history of negotiation, or whether there are voices, angles and truths we are missing. Equally, when we teach the law relating to $A D R$, are we teaching everything that will enable our students to comply with their obligations around equity and inclusion? In teaching about online dispute resolution (ODR), for example, we ought to also be teaching about how to provide for disability accessibility. ${ }^{52}$

Then, it is important to review our curricula and consider whether they include a range of experiences and voices, including those of people living at the intersection of various marginalised identities. ${ }^{53}$ Do we showcase the diverse individuals who do negotiation work? There is a predominant strain of negotiation theory that many of us probably teach, but how do other communities negotiate? How can we convey those approaches to negotiation in a way that is culturally sensitive and accurate? And who is the most appropriate person to convey that knowledge ${ }^{54}$ There will be times when we might want to include reading material that captures a narrow worldview. We can manage this in our analysis of the text and we might even set a 'critical

Rights, 22 Harv. CR-CL. L. Rev. 401, 413 (1987).

52 David Allen Larson, ODR Accessibility for Persons with Disabilities: We Must Do Better, in Online Dispute Resolution: Theory and Practice (forthcoming) provides detailed guidance.

53 Recognising that intersectional experiences differ drastically from the experiences of people who are discriminated against on a single axis like gender: Kimberlé Crenshaw, Demarginalizing the Intersection of Race and Sex: A Black Feminist Critique of Antidiscrimination Doctrine, Feminist Theory and Antiracist Politics, University of Chicago Legal Forum 139 (1989).

54 If teaching in a jurisdiction with an indigenous population, collaborating with the local indigenous community may be the more appropriate way to teach material about indigenous dispute resolution: Kwaymullina, supra note 21 at 7. 
reading ${ }^{55}$ assignment, priming students to come prepared to discuss which ideas and voices are privileged or missing.

When we think about what it means to achieve balance between perspectives in a curriculum, does that mean that we ought to align our curricula with the relative census percentages of different groups? Maybe. But we ought to be forgiven, I think, if we throw out the entire blueprint for what we did before and start afresh, prioritising those voices that traditionally do not get much of a platform in the negotiation space at all. Our students will learn modern Eurocentric negotiation quickly once on the job. Do we serve them better by strengthening a muscle that they have been flexing all their lives and will continue to flex in the legal profession as it currently is? Or do we provide them with some different tools and perspectives so that they can engage critically with the standard commercial negotiation techniques and do even better for their clients, themselves, and their colleagues?

When it comes to power, are we honest about what our students might face in the world? ${ }^{56}$ I do not want to admit, perhaps even to myself, that my experience has been that identity will likely shape strategies and outcomes. ${ }^{57}$ For example, women do ask but research shows that they achieve worse outcomes despite this -

55 DiYanni and Borst, supra note 4 at 182.

56 Michael Wheeler, Is Teaching Negotiation Too Easy, Too Hard, or Both?, 22(2) Negotiation Journal 187, 190-192 (discussing how we teach about power) (2006).

57 Sometimes our teaching can set our students up to be let down when negotiating in the real world: Elaine M. Landry and Anne Donnellon, Teaching Negotiation with a Feminist Perspective, 15(1) Negotiation Journal 21, 22 (1999). This issue is compounded when students possess identities that the teacher cannot relate to due to a lack of personal experience: 23 . 
so, in the face of institutional sexism, it might be quite a rational decision not to ask but to try a different means of attaining what one wants. ${ }^{58}$

On the topic of power, when we teach students about how to improve their alternatives and use objective criteria, do we teach about meta-strategy? By metastrategy I mean improving the BATNA of entire groups by attacking structural power imbalances; or for those on the advantageous end of power imbalances, imbuing a sense of inclusivity and equity into their negotiation ethics. ${ }^{59}$ For example, if you are a woman and you know that women might fare worse if they ask for things in the workplace, are you engaging in long-lasting BATNA-improving activities? Having access to market salary information would improve your salary negotiating position, and if that data does not exist, you might decide to band together with others to gather and publish it. We do not stop doing the work of dismantling structural sexism, but meta-strategy can help us improve our position as marginalised people across a certain set of negotiations. One of the critiques of negotiation is that it individualises systemic issues, ${ }^{60}$ but meta-strategy is a way to collectivise and use negotiation strategy at the systemic level.

One of the challenges of this work is that interventions that are inclusive for one group might exclude another. For example, at the University of Western

58 Rebecca Hollander-Blumoff, It's Complicated: Reflections on Teaching Negotiation for Women, 62 Washington University Journal of Law and Policy 77, 82 (2020). See also Annette Gainsford, Connection to Country - Place-based Learning Initiatives Embedded in the Charles Sturt University Bachelor of Law, 28 Legal Education Review 1 (2018).

59 Wheeler identifies the teaching of ethics as a significant challenge for negotiation teachers, noting that we often provoke debates with a paucity of deep moral reasoning, and these discussions achieve little or no resolution: Wheeler, supra note 56 at 189-190.

60 Mamo, supra note 51 at 29. 
Australia, incoming law students participate in a river walk to learn about indigenous history.$^{61}$ Depending on the design of the activity, it could be exclusionary for people with certain disabilities. Inclusive design might require vehicular transportation between locations. Conversations with indigenous leaders would of course need to take place in order for the design to respect the objective of the activity.

In doing the work of creating an inclusive classroom, we need to seek institutional support - or if it is not available, we must ask for it. ${ }^{62}$ Who can you speak to about racial, sexuality and gender justice, and about making sure your course materials and curriculum design are accessible to people with disabilities? What can assist you with indigenising your classroom and curriculum if you are teaching in a place with an indigenous population ${ }^{63}$ We can, to some extent, learn about our students' needs through pre-class surveys, ${ }^{64}$ but this is no substitute for seeking institutional support. Collaborating with staff of diverse backgrounds might be one option, but only if you have the kind of relationship where it is appropriate to ask for that support. In building an inclusive curriculum, we must be careful not to replicate the power dynamics that we are trying to change (such as by pigeon-holing diverse

61 Kwaymullina, supra note 21 at 19.

62 See, e.g., Id. at 29. See also 14, discussing the importance of the institution reaching into the community to create a reciprocal relationship.

63 See, e.g., Id. Importantly, we must teach with indigenous peoples not about them, or we risk falling short of creating a genuinely inclusive environment: 7 . Indigenisation is something that has to happen at the faculty level, and not just within our own courses - it needs proper support and attention from the university. Kwaymullina sets out best practice principles at 17 . Finally, it is important to remember that indigenisation is related to but separate from advancing racial justice - confusing the two risks erasing the separate goal of progressing indigenous sovereignty: 24 . On teaching race and the law, see Marcelle Burns and Jennifer Nielsen, Dealing with the 'wicked' problem of race and the law: A critical journey for students (and academics), 28(2) Legal Education Review 1 (2018).

64 Harshbarger, supra note 11 at 53. 
faculty as informal diversity advisers if they have not willingly assumed such a role). At the same time, ownership and leadership of the work of inclusion must come both from people from affected communities and from willing leaders within the institution. ${ }^{65}$

\section{Teaching process}

Creating an inclusive classroom will also require dynamism and improvisation - skills that we have already developed as negotiators.

For starters, we understand how to prepare well. We know that we need to gather as much information as we can about the lived experiences of people whose identities we do not share. Particularly in circumstances where we are still learning, we need to front-load and take control where we can by, for example, practising how we might responsibly guide conversations about social change, identity and inclusion.

We can reach into our negotiation toolkits and consider which of our usual tools we might use in order to be persuasive. ${ }^{66}$ For example, how would we establish authority in a way that garners respect from students of various backgrounds? ${ }^{67}$ How can we use social proof in the classroom to more effectively implement the ethos of inclusion and integration by, for example, conveying the message that "this is just

65 See, e.g., Kwaymullina, supra note 21 at 13.

66 Cialdini, supra note 9.

67 Id. at chapter 6 . Something I experiment with is emphasising both my 'difference' (as a woman and an immigrant from a low-socioeconomic background, and as a social justice lawyer) and my 'similarity' (as a "hard core" commercial litigator). 
what we do now; jump on board or be left behind"? ${ }^{68}$ And how do we support these surface-level techniques with substantive and long-lasting persuasion? ${ }^{69}$

In an inclusive and integrated classroom, things will come up that need to be addressed: someone will say something transphobic; someone might question why we are not focusing more on commercial negotiation exercises; someone will unwittingly make an ableist joke. We have two options. We can call out and tell off. ${ }^{70}$ I personally think this is inconsistent with the ethos of transformational teaching and is a missed opportunity to educate. The other option is to consider the varying interests in the room (for those on the receiving end of the comment, to be respected as human beings; for those making the comment, to preserve their reputation and be respected in front of their peers) and to respond nimbly in a way that meets all of those interests and addresses underlying emotions. ${ }^{71}$ Our response might differ depending on the size of the class, because different interests and degrees of shame are at play. Familiar concepts like building a golden bridge $\mathrm{e}^{72}$ and enabling face saving ${ }^{73}$ assist us. It is critical for creating a safe learning space never to leave the burden of addressing discriminatory comments on those to whom they are directed. It is hard enough exhibiting difference in traditionally White and Eurocentric spaces like law

68 Id. at chapter 4.

69 There is a useful role for readings here - particularly about people's lived experiences - so that valuable class time can be used for active learning exercises and discussions.

70 On the efficacy of 'calling out', see Loretta Ross, I'm a Black Feminist. I Think Call-Out Culture is Toxic, New York Times (Aug. 17, 2019),

https://www.nytimes.com/2019/08/17/opinion/sunday/cancel-culture-call-out.html.

71 See also Anneliese A. Singh, The Racial Healing Handbook: Practical Activities to Help You Challenge Privilege, Confront Systemic Racism \& Engage in Collective Healing 18 (2019).

72 Ury, supra note 46.

73 Fisher, Ury and Patton, supra note 9 at 30. 
schools. ${ }^{74}$ As part of our preparation for our courses, we can identify ways to reduce the risk of students saying hurtful and misguided things in class. We can set ground rules for participation, and reflection as an assessment tool can support the creation of an integrated classroom through targeted questions about identity and equity. ${ }^{75}$

Finally, participation is an area of assessment that needs to be closely examined in terms of how it might privilege or disadvantage certain groups. The emphasis on vocal class participation privileges a way of interacting with people that is not common to all cultures or backgrounds. ${ }^{76}$ If participation is going to be assessed, the method by which it is assessed ought to be inclusionary. This might require some advance organisation. Instead of allowing free-form discussion, for example, you might give each student an opportunity to prepare to be called on in advance. You might also survey students as to which contributions should count for the participation grade. ${ }^{77}$ Perhaps assessment of participation should equally be based on when people do speak as well as when they create space for and encourage others to contribute. In the online space, there is the potential to reduce bias because it is easier to assess who raised a hand first or typed a comment in the chat function. ${ }^{78}$

\footnotetext{
Schwartz, supra note 16 at 12 .

See, e.g., Rhonda Magee, The Inner Work of Racial Justice (2019).

6 Eye contact and the use of silence are two aspects of communication that vary across cultures. Prioritising vocal engagement in the classroom therefore privileges one set of cultural norms: Kwaymullina, supra note 21 at 25.

77 When teaching in early 2020, I surveyed my negotiation students about their experience of learning online, including whether the 'chat function' on Zoom should count for the participation grade. My thinking was yes, and the student response confirmed my instinct, so we collectively agreed to expand our understanding of what would count as participation.

78 Ing, supra note 2 at 179.
} 


\section{Conclusion}

We have both an opportunity and an obligation as negotiation teachers to answer the call to create a more inclusive world through our teaching. Perhaps the question that best guides us in this journey is: what would attract all kinds of people to this course and make them feel like this is a safe and welcoming learning environment? For teachers with privileged identities, we might fear making mistakes. But we can reframe that sense of threat and see this work as a healthy challenge. ${ }^{79}$ We are practised at achieving the outcomes we want when negotiating, so when it comes to creating an inclusive classroom, we are well-served by drawing on our existing skills.

\section{PART III: TECHNOLOGY80}

\section{Introduction}

In this part, I consider what the shift to online dispute resolution and teaching during the pandemic means for the knowledge and skills we should include (or include more of) in our curricula in future. In the second section, I consider what aspects of pandemic teaching practices reflect transformational teaching, and should therefore be carried forward into both in-person and online courses.

\section{The content of our courses}

Pre-pandemic, many of us would have covered the usual material in our courses: positional versus interest-based negotiation, the history of ADR, recent

79 Kathleen O'Connor, Josh Arnold and Andrea Maurizio, The Prospect of Negotiating: Stress, Cognitive Appraisal, and Performance, 46 Journal of Experimental Social Psychology 729 (2010).

80 For tips and ideas for maximising the online learning space see Lillian Corbin and Lisa Bugden, Online Teaching: The Importance of Pedagogy, Place and Presence in Legal Education, 28 Legal Education Review 1. 
developments, and the research and theory on strategies and tactics for being an effective negotiator. We might also have covered ODR material, including virtual advocacy, but if we can take anything away from the pandemic, it is the particular importance of teaching specific ODR skills. ODR has long been a feature of our world, but our forced trialling of it, and our experience that it can be an effective way to resolve disputes, ${ }^{81}$ means that ODR is likely to be a far more significant part of the dispute resolution landscape in future. Teaching our students online negotiation skills involves a number of components.

First we need to canvass the history and future of online negotiation to help our students understand how negotiation might take place now and in the future. People have adapted creatively over the last 18 months. ${ }^{82}$ The pandemic is a live case study in how quickly the disputes and negotiation business can change - an important lesson in the value of having a diverse skill-set, and also a lesson in how the impossible can quickly become possible should we set our minds to it.

81 See, e.g., Kim M. Rooney, The Global Impact of the Covid-19 Pandemic on Commercial Dispute Resolution in the First Seven Months, International Bar Association (Oct. 13, 2020), https://www.ibanet.org/Article/NewDetail.aspx?ArticleUid=bd404ce3-3886-48a8-98f638eaaccd5f53.

82 See, e.g., Guidance Note on Possible Measures Aimed at Mitigating the Effects of the Covid-19 Pandemic, International Chamber of Commerce (Apr. 9, 2020), https://iccwbo.org/publication/iccguidance-note-on-possible-measures-aimed-at-mitigating-the-effects-of-the-covid-19-pandemic/; Online Practice Tools, American Bar Association, https://www.americanbar.org/groups/dispute resolution/resources/resources-for-mediatingonline/ (last visited Apr. 25, 2021); Joe McIntyre, Anna Olijnyk and Kieran Pender, Civil courts and Covid-19: Challenges and opportunities in Australia, 45(3) Alternative Law Journal 195 (2020); Remote Courts, The Practice (Jul-Aug. 2020), https://thepractice.law.harvard.edu/issue/volume-6issue-5/; Covid-19, Kluwer Mediation Blog, http://mediationblog.kluwerarbitration.com/category/covid-19/ (last visited Apr. 25, 2021); Katie Shonk, Online Negotiation in a Time of Social Distance, Harvard PON Daily Blog (Mar. 26, 2020), https://www.pon.harvard.edu/daily/negotiation-skills-daily/online-negotiation-in-a-time-ofsocial-distance/; Hal Movius, How to Negotiate - Virtually, Harvard Business Review (Jun. 10, 2020), https://hbr.org/2020/06/how-to-negotiate-virtually. 
In terms of what specifically to teach, we need to teach when and how to negotiate online. What tactics are effective and persuasive on virtual platforms versus email? ${ }^{83}$ And how do these differ from the negotiation techniques we might use in person? For example, eye contact and body language etiquette needs to change, and there are opportunities for creative ways to collaborate (such as sharing screens and documents). ${ }^{84}$ We also need to have a discussion about effective negotiation preparation - confidentiality and data security need to be considered, and contingency plans need to be put in place for when things go wrong (like equipment failing). Taking this one step further, exercises could include technological failure, so that students can practise how they would manage to preserve the flow of the negotiation. It is even possible to conduct experiential learning online. ${ }^{85}$

Another benefit of online courses, available as an add-on to in-person courses, is bringing guests into the classroom through virtual platforms. This is not only environmentally friendly, but also opens up a suite of potential speakers. Role plays can also be conducted with students from other countries, enhancing access to experiencing different cultural approaches. ${ }^{86}$

83 Noam Ebner, Negotiation via Videoconferencing, in The Negotiator's Desk Reference 151 (C Honeyman and AK Schneider eds., 2017); Charles B. Craver, How to Conduct Effective Telephone and E-Mail Negotiations (October 7, 2015).

84 Id.

85 Like, for example, the mediation clinic that was run online by Professor Alexandra Carter at Columbia Law School during the 2020-2021 academic year. See also supra note 28.

86 For the results of an experiment along these lines, see Remigiusz Smolinski and Peter Kesting, Transcending the Classroom: A Practical Guide to Remote Role Plays in Teaching International Negotiation, 28(4) Negotiation Journal 489 (2012). 


\section{Technology and teaching process}

My observation is that it took a major disruption to traditional teaching methods (going online) in order for us university teachers to more substantially adopt transformational teaching practices. Part of this was to do with the immediate need for compassion towards our students (which I discuss more in Part IV), and part of it was driven by experiences of 'Zoom fatigue' and the perception that students would not attend recorded classes if they were not delivered in an engaging way. 'Zoom fatigue', the idea of being especially exhausted by excessive time spent on virtual platforms, is a real phenomenon. People struggle to look at faces close up, including their own, for long periods of time. ${ }^{87}$ People are also less able to use space in ways they might have were they meeting in-person, such as by moving around or using a whiteboard. ${ }^{88}$ In order to combat Zoom fatigue and keep students engaged, the following were practices that I used as a teacher and that I experienced as a student.

Class formats changed. Some teachers largely abandoned lecturing and instead facilitated student-led discussions, teasing out common threads and themes. Discussion-based classes were often paired with 'reading response papers' submitted in advance of the class. ${ }^{89}$ Some classes were still run in a more structured way, with blocks of participatory activities (whether that be discussing the readings, writing contributions into the chat function, or participating in small-group discussion in breakout rooms), but what was common across courses was a shift away from

87 Geraldine Fauville et al., Zoom Exhaustion \& Fatigue Scale (Feb. 15, 2021), https://papers.ssrn.com/sol3/papers.cfm?abstract id=3786329.

88 Id.

$89 \sim 500$ word submissions either by email or on an online discussion board containing thoughts about that week's readings. 
knowledge delivery during class (front-loading it instead through reading assignments) and towards active learning. The ubiquitous presence of technology expanded the activities that were possible - such as polling, keeping a written record of contributions (from the chat function), collaboration through tools like Google documents, ${ }^{90}$ and interaction through tools like Mentimeter. ${ }^{91}$

Multiple channels of participation were utilised such as the chat function, polling, and regular verbal contributions. There was also more effort by teachers to spell out and negotiate 'rules of engagement', such as whether breakout room discussions would be confidential, how the chat function would be used, and whether people could interrupt or would need to raise their hand. All of this seemed to improve communication in my online classrooms.

In terms of community, it largely fell to teachers to think about how to create community in the absence of the organic connections that might arise on campus. Breakout rooms were crucial. Even though they were often intended to be used for active learning exercises, we students used them to get to know each other. Breakout rooms were therefore more important for class community than any other intervention, like encouraging people to come to class early to socialise. Another effective method of creating community was project work in groups or pairs. Helpfully, negotiation courses already lend themselves to creating class community

90 See, e.g., Ing, supra note 2 at 178 who used a Google document where students could type responses and comments in lieu of verbal discussions. Feedback from students was positive, particularly because they had a written record of class discussions from which they could build a set of study notes.

91 https://www.mentimeter.com/. 
because students have natural connection points through role plays (and building rapport is a crucial skill and so is something that students readily engage in).

The classroom was redefined. We had to get comfortable with dialling in from a variety of locations (couches, offices, kitchen counters) and in a variety of conditions (with family around, eating snacks or drinking coffee). All spaces, virtual and physical, were maximised. Small groups could more easily be re-shuffled compared to a physical classroom where people are usually grouped with whoever they are sitting nearest to. The ability to 'show and tell' objects (or pets!) enabled us to bring more of our whole selves to class, and we could also engage in creative activities with access to more belongings at home. Engaging in mindfulness practices was also less awkward because we could turn cameras off and sit, stand, or lie down. Importantly, the Zoom classroom facilitated a more horizontal teacher-student relationship: everyone was the same size on the screen and beaming in from home was an equalising experience. For me, not needing to commute also freed up time in my schedule. I achieved a significantly improved work-life balance.

Class size mediated what was possible. Small classes lent themselves well to student-led discussions. Easy-to-use tools (polls, interactive presentations, the chat function) were particularly important in large classes. But, if I were teaching online to a class of over 50 students again, I would think carefully about whether it would be more appropriate to adopt an entirely different format. For example, it might be best to 'flip' lectures, conducting knowledge delivery through recorded videos and utilising a set of active learning exercises (quizzes, discussion boards, tutorial-style classes). 
In terms of assessment, there was a far larger number of assignments generally and a large proportion of assignments that were reflective. There was also more creativity in the nature of assignments, relying not just on the discussion boards on learning management systems, but also video assignments, and in the class that I taught, a self-marking quiz. Overall, there seemed to be more receptivity to 'breaking the mould' of traditional law school assessment formats.

Finally, in terms of feedback, tools like SurveyMonkey and Google Forms ${ }^{92}$ were used before, during and at the end of courses to seek information and feedback from students. I did not use or observe the use of polling for real-time feedback, but I did use polls to create more interaction and engagement in my lectures.

What we see is that many of these practices are transformational teaching practices: depth was prioritised over breadth; there were copious opportunities for students to link new knowledge to their existing contexts; classrooms were engaging and active; we could repeat and practice knowledge and develop skills through outof-class assessments; dynamic communities arose; teacher-student relationships reflected the ethos of intellectual coaching as opposed to hierarchical knowledge transfer; pre-course surveys helped teachers gather important information and midterm feedback assisted them in course correcting; and broad, open-ended reflective assignments gave students the opportunity to engage in adventure learning and try

92 I used Google Forms for mid-semester feedback for the first time in early 2020. I will continue to use Google Forms in future both for in-person and online courses because more detailed questions can be compiled and completed quickly on a computer (compared to in-person or handwritten feedback). For example, you can use multi-choice questions, linear scales, and openended text boxes. In order to increase survey completion rates, I recommend giving students 5-10 minutes during class to complete feedback surveys, otherwise multiple reminders will be required. 
out their newfound skills and knowledge in their own lives. These practices already existed before the pandemic, however, what is different now is that all teachers have upskilled and experienced the benefits of transformational practices first hand. Beyond bringing our new skills into our post-pandemic teaching, we now understand the importance of experimenting and disrupting our old teaching patterns.

At the same time, I observed that there is a lot that was not fully explored during online teaching in the pandemic, like experiential and adventure learning, role play design, retrieval practice through quizzing, a more capacious use of polling to test students' understanding, ${ }^{93}$ and the use of artificial intelligence tools. ${ }^{94}$

We can continue exploring these aspects when teaching in-person or online in future: we can use learning management systems to set assessments that encourage repetition and retrieval (quizzes), and community creation and reflection (discussion boards); we can add avenues for participation (such as enabling the sending of messages to the teacher in real time); we can use interactive and collaborative tools to enhance engagement (especially useful for large classes); we can play around with space (by delivering some content on virtual platforms) and time (by flipping lectures); and we can use feedback / course correction tools (like polling software). ${ }^{95}$ Prepandemic research found that feelings of community and connection were higher for

93 DiYanni and Borst, supra note 4 at 49. See Corbin and Bugden, supra note 80 at 8 for polling software ideas.

94 There are various apps and programs available that are worth investigating because of the flexibility they offer for adjusting role play scenarios: Samuel Dinnar et al., Artificial Intelligence and Technology in Teaching Negotiation, 37(1) Negotiation Journal 65 (2021). See also Jonathan Gratch, David DeVault and Gale Lucas, The Benefits of Virtual Humans for Teaching Negotiation at the International Conference on Intelligent Virtual Agents (Sep. 2016); Moffat and Wallin, supra note 36 at 7.

95 Corbin and Bugden, supra note 80 at 8 . 
in-person students than online students, ${ }^{96}$ so activities and tools like collaborative assignments, photo blogs, video-recording and sharing negotiations, online office hours, Social Media, small discussion groups, buddy systems, and chat rooms will be important for online-only courses. ${ }^{97}$

There is also the quite separate question of what role online-only courses should have post-pandemic. This may be an institutional question over which we do not have significant control. Here it is important to remember that online-only courses already existed pre-pandemic and were supported by academic literature grounded in best practices pedagogy. ${ }^{98}$ I have personally found the online courses I have undertaken in my post-graduate study to be some of the best I have ever participated in. It is exciting to see that online pedagogy is continuing to develop in interesting ways. Ebner and Greenberg take the novel approach of considering how negotiation courses might be made "bingeworthy" after observing that many people seemed not to experience screen fatigue when bingeing TV shows during the pandemic. $^{99}$

96 Jennifer D. Parlamis and Lorianne D. Mitchell, Teaching Negotiations in the New Millennium: Evidence-Based Recommendations for Online Course Delivery, Negotiation Journal 93, 103, 105, 108 (2014). Although, both sets of students perceive an improvement in their negotiation competency after course completion.

97 Id at 107. While at Columbia Law School, we had a particularly active LLM chat group on WhatsApp, which helped (me at least) with building community from afar. If conducting a precourse survey, it would be a good idea to include questions about what helps students feel as though they are part of a community.

98 Ebner, supra note 2.

99 Elayne Greenberg and Noam Ebner, Designing binge-worthy courses: Pandemic pleasures and COVID-19 consequences, 36(4) Negotiation Journal 535-560 (2020). 


\section{Conclusion}

In this part, I considered how our collective shift into the online space should change what we ought to be teaching. I then reflected on what lessons we can take away from our technological upskilling to improve in-person and online teaching in future.

\section{PART IV: EQUIPPING OUR STUDENTS TO MEET THE DEMANDS OF THE MODERN WORLD}

\section{Introduction}

In this part, I consider how we might accommodate the fact that the pandemic has changed us, and the world, in our teaching. I then discuss the opportunity we have to overhaul our curricula to answer the pre-pandemic call to properly equip law students with the range of skills they need to navigate the modern world. ${ }^{100}$

\section{Taking our changed world into account in our teaching}

The pandemic has been a life-changing experience beyond simply mastering virtual platforms and online learning management systems. For many of us, ${ }^{101}$ our concerns in 2020 were vastly different from the concerns we had pre-pandemic. Would we have enough work? How would we learn effectively at university? How could we protect our loved ones? And was somebody paying the healthcare workers enough

100 See, e.g., Menkel-Meadow, supra note 43. See also Inspiring National Indigenous Education for Aotearoa New Zealand's Bachelor of Laws Degree (2020) and Barbara Billingsley, Trevor Farrow and Joshua Sealy-Harrington, Webinar: A conversation about Access to Justice and Systemic Racism, YouTube (Oct. 20, 2020), https://www.youtube.com/watch?v=zwxPK0Oaf10.

101 This section is grounded in my experiences and my observations of the experiences of people with whom I have contact. Not everyone experienced the shift that the pandemic brought in the same way: "All my life I have lived with the chronic fever of antiblack racism. ... I know, as many do, that I've been living a pandemic all my life; it is structural rather than viral; it is the global state of emergency of antiblackness. What the COVID-19 pandemic has done is expose even further the endoskeleton of the world": Brand, supra note 3. 
that they would do their best work during this crucial time? 2020 required us to drastically change our expectations and offered a collective reminder that we must never take the basics for granted - food, shelter, health, family, and connection. These experiences can and should inform our teaching. The world has changed ${ }^{102}-$ and our students with it. Although there will be some common threads, which emerge more clearly over time, what we take from the experience of the pandemic differs for all of us. ${ }^{103}$ In this section I aim to stimulate thinking about how our changed perspectives might inform curriculum design and teaching process.

For example, if the pandemic has taught us about the importance of family, how might this affect the capaciousness with which we now approach curricula that traditionally focused on commercial negotiation? Is there value in encouraging our students to learn about communication skills in their close relationships, not only to deepen their professional abilities, but to help them create a stronger foundation for their lives and their psychological wellbeing? If I have learned something about the importance of nurturing family relationships and being generous with the love one gives to those (sometimes difficult) people who have known us since birth, I might:

- $\quad$ add as a learning outcome the ability to apply communication skills in one's personal life in order to strengthen relationships, recognising the importance of personal and professional relationships to one's life outcomes;

102 See, e.g., Coronavirus Will Change the World Permanently, Here's How, Politico Magazine (Mar. 19, 2020, 07:30 PM), https://www.politico.com/news/magazine/2020/03/19/coronavirus-effecteconomy-life-society-analysis-covid-135579.

103 Pre-course surveys of our students can help us better understand what matters to them now: see Harshbarger, supra note 11. 
- include role play scenarios based on one-on-one conversations with family or friends - including the negotiation of intangibles like the extent to which we are given space to be heard and seen as people;

- $\quad$ set 'adventure learning' ${ }^{104}$ assessments that encourage students to connect more deeply with their peers, communities and/or loved ones; and

- articulate better arguments when engaging with academic institutions grounded in tangible feedback from students elicited through targeted questions - about how my work supports student psychological wellbeing ${ }^{105}$ and why it should, therefore, be an expanded or compulsory offering.

Another common experience we might have shared is seeing the wholeness of people - Zooming into people's homes and having more honest conversations about what is going on in people's personal lives in order to recalibrate expectations. We have had to be more flexible and compassionate as teachers than we might have been in the past, showing us the relative ease with which we can shift away from a hierarchical model of teaching to a transformative approach and bridge the divide that our universities tend to maintain between academic and pastoral functions. ${ }^{106}$ In my experience of bringing more pastoral care into my teaching, I have been able to appreciate who my students are as people, I have learned to trust my students more, and I have seen that there is no real harm in being generous and flexible with

\footnotetext{
104 Supra note 27.

105 Duffy and Field, supra note 47 at 13.

106 That is, the teachers who teach versus the staff who look after students.
} 
deadlines. I think that all of this has strengthened my teacher-student relationships and created a more fruitful environment for learning. ${ }^{107}$ From my perspective as a student, the inclusion of self-awareness practices through mindfulness assignments significantly enhanced my focus, productivity and well-being. So including reflective and awareness practices in our curricula is another way that we can teach both an important skill-set for effective negotiation and provide pastoral care to our students.

There are many other angles we could take, like looking at case studies of persuasive public health communication in order to teach our students about persuasion and its broad applicability when negotiating with people about their behaviour en masse. Public messaging might connect into new avenues of social change work that students are interested in as a result of the pandemic, which might also link into "meta-strategy" and improving the collective BATNA of entire groups of marginalised people. All in all, the pandemic is a reminder that we have an opportunity, as teachers, to display the breadth of the world to which negotiation theory and strategy applies. I discuss this more next.

\section{Answering the call to provide capacious legal education}

In Part I, I stated that we need to teach our students what they need to know in order to successfully navigate the modern world. One of the critiques of legal education is that it generally fails to do so. Menkel-Meadow argues that, in legal education, we focus on too narrow a 'law job': ${ }^{108}$

\footnotetext{
107 Pastoral care from teachers is also particularly important for the success of students with cultural worldviews that take a holistic approach to a person's wellbeing: Schwartz, supra note 16 at 18.

108 Menkel-Meadow, supra note 43 at 133-134.
} 
"... instead of "too many lawyers" or "too much legal education," we should be educating law students to do other things (e.g., solve problems, as well as litigate disputes, provide services to those with inadequate access, create new organizations to deal with new problems, work productively in both the private and public sector to build collaborative institutions to address modern problems, and think synthetically, rather than only analytically) ... it is not that we have too many lawyers and not enough jobs, but that we do not have enough justice or proper allocation to the kinds of things that a legal education could be directed to for the purpose of improving our social condition".

In teaching negotiation, we are already providing an offering that can be applied broadly to law and non-law jobs across various sectors. At the same time, there is more that we could be doing to help our students see the full scope of how negotiation theory and strategy could be applied. There are at least two spaces I can think of where we can extend ourselves: identifying trends and opportunities in ODR and taking advantage of them; and strategising towards social change.

Teaching students about trends and opportunities in ODR - and how to identify them - is an important part of preparing our students for post-university life. This is particularly so considering that ODR is now even more firmly entrenched as a legitimate option for dispute resolution. ${ }^{109}$ There are many interesting and important commercial and public sector initiatives going on to help modernise the legal profession and to enhance access to justice - but there are also significant untapped opportunities. ${ }^{110}$ There will be so much more that students can do with their law degrees if they are taught to think more creatively about what is possible.

In terms of strategising towards social change, interests analysis, listening skills and conflict resolution abilities will enable students to collaborate effectively with

\footnotetext{
109 Supra note 81.

110 See, e.g., Access to justice through leveraging legal technology, Thomson Reuters Blog (Aug. 22, 2019), https://blogs.thomsonreuters.com/legal-uk/2019/08/22/access-to-justice-throughleveraging-legal-technology/.
} 
other people, groups and movements - across difference - in social change work. ${ }^{111}$ The processes we teach will equip our students with tools for identifying a range of options for progressing the social movements they are interested in. And finally, the substantive content we teach about dispute resolution systems will help them progress change smoothly, efficiently, and peacefully.

How might we implement some of these concepts in our curricula? Learning outcomes might be expanded or amended to include understanding the use of negotiation skills to collaborate effectively to advance social change initiatives. Different role play scenarios can help us present a capacious view of the applicability of negotiation skills to different goals, like a simulation based on achieving agreement about the role of the Police in schools (if any) in a community meeting scenario. We could get creative about what we mean by 'readings'. I have traditionally drawn from journal articles and textbooks. There are other media - videos, podcasts, art, theatre - that offer excellent learning material, especially access to voices that are not traditionally given a platform in law schools. Finally, as teachers of skills-based courses, we have a unique opportunity to connect with practitioners from different backgrounds and enlist them to enhance our courses. Collaborating with practitioners from different areas also keeps our ears close to the ground about the kinds of skills students need to learn. ${ }^{112}$

\footnotetext{
111 See, e.g., Mamo, supra note 51.

112 Germain-Thomas and colleagues experimented with a role play design exercise involving external professionals, which students found valuable: Germain-Thomas et al., supra note 30 at 387, 390, 395-396, 398.
} 


\section{Conclusion}

In striving towards our aim of being transformational teachers, the recent break in our old teaching patterns is an opportunity to upgrade our courses and answer the prepandemic call to equip our students to meet the demands of the modern world. We can and should draw on lessons from the pandemic in recognition of the fact that modern demands have themselves drastically evolved and will continue to do so.

\section{CONCLUSION}

The purpose of this paper has been to highlight lessons and opportunities for negotiation teaching arising from the pandemic, and to assess and discuss them in relation to teaching best practice. I have focused on three themes: creating inclusive and integrated classrooms; the role of technology; and equipping our students to meet the demands of the modern world. Teaching online has led to a collective upskilling in our understanding of our students, of what matters in life, and of how technology can enhance our teaching. We have agency in our classrooms to help create a more equitable world, as we indeed need to, if we are going to be transformational teachers and serve all of our students as best as we can. 


\section{BIBLIOGRAPHY}

\section{BOOKS AND BOOK CHAPTERS}

1. Peter C. Brown, Henry L. Roediger III and Mark A. McDaniel, Make it stick: The science of successful learning (2014)

2. Robert Cialdini, Influence: The Psychology of Persuasion (2006)

3. Robert DiYanni and Anton Borst, The Craft of College Teaching: A Practical Guide (2020)

4. Carol Dweck, Mindset (2007)

5. Noam Ebner, Negotiation via Videoconferencing, in The Negotiator's Desk Reference (C Honeyman and AK Schneider eds., 2017)

6. Robert Fisher, William Ury and Bruce Patton, Getting to Yes (2011)

7. Christopher Honeyman, James Coben and Giuseppe De Palo (eds), Venturing Beyond the Classroom (2010)

8. Ong Ee Ing, The year of COVID-19: Personal reflections on how traditional pedagogy can be informed by online teaching methods (aka how I changed my mind about online teaching), in Law and COVID-19 (Aurelio Gurrea-Martínez, Mark Findlay and Goh Yihan, eds., 2020)

9. Rhonda Magee, The Inner Work of Racial Justice (2019)

10. Charles Mills, The Racial Contract (1997)

11. Anneliese A. Singh, The Racial Healing Handbook: Practical Activities to Help You Challenge Privilege, Confront Systemic Racism \& Engage in Collective Healing (2019)

12. William Ury, Getting Past No: Negotiating Your Way From Confrontation to Cooperation (1993)

13. Michael Wheeler, The Art of Negotiation: How to Improvise Agreement in a Chaotic World (2013)

14. Howard Zinn, You Can't Be Neutral on a Moving Train: A Personal History of Our Times (2002) 


\section{JOURNAL ARTICLES}

15. Arvid Bell and Taylor Valley, The Art of Negotiation Exercise Design: Five Basic Principles to Produce Powerful Learning Experiences, Negotiation Journal 57 (2020)

16. Robert Bordone and Chad Carr, Critical Decisions in Negotiation: A New Video Resource for Teaching Negotiation, 29(4) Negotiation Journal 463 (2013)

17. Darshan Brach, A Logic for the Magic of Mindful Negotiation, 24(1) Negotiation Journal 25 (2008)

18. Marcelle Burns and Jennifer Nielsen, Dealing with the 'wicked' problem of race and the law: A critical journey for students (and academics), 28(2) Legal Education Review 1 (2018)

19. Anna Cody, Developing Students' Sense of Autonomy, Competence and Purpose Through a Clinical Component in Ethics Teaching, 29 Legal Education Review 1 (2019)

20. Lillian Corbin and Lisa Bugden, Online Teaching: The Importance of Pedagogy, Place and Presence in Legal Education, 28 Legal Education Review 1 (2018)

21. Kimberlé Crenshaw, Demarginalizing the Intersection of Race and Sex: A Black Feminist Critique of Antidiscrimination Doctrine, Feminist Theory and Antiracist Politics, University of Chicago Legal Forum 139 (1989)

22. Richard Delgado et al., Fairness and Formality: Minimizing the Risk of Prejudice in Alternative Dispute Resolution, 6 Wis. L. Rev. 1359 (1985)

23. Samuel Dinnar et al., Artificial Intelligence and Technology in Teaching Negotiation, 37(1) Negotiation Journal 65 (2021)

24. Daniel Druckman and Noam Ebner, Discovery Learning in Management Education: Design and Case Analysis, 42(3) Journal of Management Education 347 (2018)

25. James Duffy and Rachael Field, Why ADR must be a mandatory subject in the law degree: A cheat sheet for the willing and a primer for the non-believer, 25(1) Australasian Dispute Resolution Journal 3 (2014)

26. Noam Ebner and Joan Stearns Johnsen, Mismatches between mediation teaching and practice: A first community conversation, 1 ACResolution 16 (2019)

27. Liam Elphick, Adapting Law Lectures to Maximise Student Engagement: Is it Time to 'Transform'?, 28 Legal Education Review 1 (2018) 
28. Warwick Fisher et al., Student Evaluations: Pedagogical Tools or Weapons of Choice?, 30 Legal Education Review 1 (2020)

29. Annette Gainsford, Connection to Country-Place-based Learning Initiatives Embedded in the Charles Sturt University Bachelor of Law, 28 Legal Education Review 1 (2018)

30. Patrick Germain-Thomas et al., Collaborative Role-Play Design: Teaching Negotiation through a Novel Student-Business Partnership, Negotiation Journal 387 (2019)

31. Elayne Greenberg and Noam Ebner, Designing binge-worthy courses: Pandemic pleasures and COVID-19 consequences, 36(4) Negotiation Journal 535 (2020)

32. Denise Harshbarger, Universal Design for Learning (UDL): A beginner's guide for online higher education instructors, 4 Journal of Online Higher Education 51 (2020)

33. Rebecca Hollander-Blumoff, It's Complicated: Reflections on Teaching Negotiation for Women, 62 Washington University Journal of Law and Policy 77 (2020)

34. Eva Feder Kittay, When Caring Is Just and Justice Is Caring: Justice and Mental Retardation, 13(3) Public Culture 557 (2001)

35. Lawrence Krieger and Kennon Sheldon, What Makes Lawyers Happy?: A DataDriven Prescription to Redefine Professional Success, 83 Geo. Wash. L. Rev. 554 (2015)

36. Ambelin Kwaymullina, Teaching for the 21st Century: Indigenising the law curriculum at UWA, 29 Legal Education Review 1 (2019)

37. Elaine M. Landry and Anne Donnellon, Teaching Negotiation with a Feminist Perspective, 15(1) Negotiation Journal 21 (1999)

38. Vicci Y.J. Lau, How to Encourage Student Voice: Obtaining Effective Feedback from Law Students in Course Evaluation, 29 Legal Education Review 1 (2019)

39. Ian Macduff, Using Blogs in Teaching Negotiation: A Technical and Intercultural Postscript, 28(2) Negotiation Journal 201 (2012)

40. Bobbi McAdoo and Melissa Manwaring, Teaching for Implementation: Designing Negotiation Curricula to Maximize Long-Term Learning, 25(2) Negotiation Journal 195 (2009) 
41. Joe McIntyre, Anna Olijnyk and Kieran Pender, Civil courts and Covid-19: Challenges and opportunities in Australia, 45(3) Alternative Law Journal 195 (2020)

42. Carrie Menkel-Meadow, Crisis in Legal Education or the Other Things Law Students Should Be Learning and Doing, 45 McGeorge L. Rev. 133 (2013)

43. Felix E. Mezzanotte, Do (Underperforming) Students Benefit from a Flipped Lecture? Evidence from Business Students Studying Company Law, 28 Legal Education Review 1 (2018)

44. Diane Moffat and Kenneth Mark Wallin, An Examination of Online Course Design, 2 Journal of Online Higher Education 1 (2018)

45. Kathleen O'Connor, Josh Arnold and Andrea Maurizio, The Prospect of Negotiating: Stress, Cognitive Appraisal, and Performance, 46 Journal of Experimental Social Psychology 729 (2010)

46. Jennifer D. Parlamis and Lorianne D. Mitchell, Teaching Negotiations in the New Millennium: Evidence-Based Recommendations for Online Course Delivery, Negotiation Journal 93 (2014)

47. Bruce Patton, The Deceptive Simplicity of Teaching Negotiation: Reflections on Thirty Years of the Negotiation Workshop, 25(4) Negotiation Journal 481 (2009)

48. Gary Peller, Legal Education and the Legitimation of Racial Power, 65(2) Journal of Legal Education 405 (2015)

49. Chrysi Rapanta et al., Online University Teaching During and After the Covid-19 Crisis: Refocusing Teacher Presence and Learning Activity, 2 Postdigital Science and Education 923 (2020)

50. Leonard Riskin and Rachel Wohl, Mindfulness in the Heat of Conflict: Taking Stock, 20 Harvard Negotiation Law Review 121 (2015)

51. Justine Rogers, Teaching Soft Skills Including Online: A Review and Framework 30 Legal Education Review 1 (2020)

52. Melanie Schwartz, Retaining Our Best: Imposter Syndrome, Cultural Safety, Complex Lives and Indigenous Student Experiences of Law School, 28 Legal Education Review 1 (2018)

53. George M. Slavich and Philip G. Zimbardo, Transformational Teaching: Theoretical Underpinnings, Basic Principles, and Core Methods, 24 Educational Psychology Review 569 (2012) 
54. Remigiusz Smolinski and Peter Kesting, Transcending the Classroom: $A$ Practical Guide to Remote Role Plays in Teaching International Negotiation, 28(4) Negotiation Journal 489 (2012)

55. Laurie Squillaci, Mindfulness as a Tool for Student Achievement in Higher Education: Insights, Benefits, and Exercises, 2 Journal of Online Higher Education 1 (2018)

56. Michael Wheeler, Is Teaching Negotiation Too Easy, Too Hard, or Both?, 22(2) Negotiation Journal 187 (2006)

57. Patricia Williams, Alchemical Notes: Reconstructing Ideals from Deconstructed Rights, 22 Harv. CR-CL. L. Rev. 401 (1987)

\section{INTERNET MATERIALS}

58. Access to justice through leveraging legal technology, Thomson Reuters Blog (Aug. 22, 2019), https://blogs.thomsonreuters.com/legaluk/2019/08/22/access-to-justice-through-leveraging-legal-technology/

59. Barbara Billingsley, Trevor Farrow and Joshua Sealy-Harrington, Webinar: $A$ conversation about Access to Justice and Systemic Racism, YouTube (Oct. 20, 2020), https://www.youtube.com/watch?v=zwxPKOOaf1Q

60. Best Practices for Online Teaching, Mitchell Hamline School of Law (May. 21, 2020), https://mitchellhamline.edu/dispute-resolutioninstitute/2020/05/21/presentation-mitchell-hamline-best-practices-for-onlineteaching/

61. Best Practices: Online Pedagogy, Harvard University, https://teachremotely.harvard.edu/best-practices (last visited Apr. 23, 2021)

62. Dionne Brand, On narrative, reckoning and the calculus of living and dying, Toronto Star (Jul. 5, 2020), https://www.thestar.com/entertainment/books/2020/07/04/dionne-brandon-narrative-reckoning-and-the-calculus-of-living-and-dying.html

63. Marcus Buckingham and Ashley Goodall, The Feedback Fallacy, Harvard Business Review (Mar-Apr. 2019), https://hbr.org/2019/03/the-feedbackfallacy

64. Coronavirus Will Change the World Permanently, Here's How, Politico Magazine (Mar. 19, 2020, 07:30 PM), https://www.politico.com/news/magazine/2020/03/19/coronavirus-effecteconomy-life-society-analysis-covid-135579 
65. Covid-19, Kluwer Mediation Blog,

http://mediationblog.kluwerarbitration.com/category/covid-19/ (last visited Apr. 25, 2021)

66. Daphne M. Davis and Jeffrey A. Hayes, What are the benefits of mindfulness, American Psychological Association (Jul-Aug. 2012), https://www.apa.org/monitor/2012/07-08/ce-corner

67. Diversity wins: How inclusion matters, McKinsey \& Company (May. 19, 2020), https://www.mckinsey.com/featured-insights/diversity-andinclusion/diversity-wins-how-inclusion-matters

68. Education and inclusion should be human rights priorities, UN Assembly hears, UN News (Nov. 1, 2019), https://news.un.org/en/story/2019/11/1050431

69. Vijay Eswaran, The business case for diversity in the workplace is now overwhelming, World Economic Forum (Apr. 29, 2019), https://www.weforum.org/agenda/2019/04/business-case-for-diversity-inthe-workplace/

70. Great Reset, Time, https://time.com/collection/great-reset/ (last visited Apr. 24, 2021)

71. Hal Movius, How to Negotiate - Virtually, Harvard Business Review (Jun. 10, 2020), https://hbr.org/2020/06/how-to-negotiate-virtually

72. Online Practice Tools, American Bar Association, https://www.americanbar.org/groups/dispute resolution/resources/resources -for-mediating-online/ (last visited Apr. 25, 2021)

73. Remote Courts, The Practice (Jul-Aug. 2020), https://thepractice.law.harvard.edu/issue/volume-6-issue-5/

74. Kim M. Rooney, The Global Impact of the Covid-19 Pandemic on Commercial Dispute Resolution in the First Seven Months, International Bar Association (Oct. 13, 2020), https://www.ibanet.org/Article/NewDetail.aspx?ArticleUid=bd404ce3-388648a8-98f6-38eaaccd5f53

75. Loretta Ross, I'm a Black Feminist. I Think Call-Out Culture is Toxic, New York Times (Aug. 17, 2019), https://www.nytimes.com/2019/08/17/opinion/sunday/cancel-culture-callout.html

76. Katie Shonk, Online Negotiation in a Time of Social Distance, Harvard PON Daily Blog (Mar. 26, 2020), https://www.pon.harvard.edu/daily/negotiation-skillsdaily/online-negotiation-in-a-time-of-social-distance/ 
77. The Great Reset, World Economic Forum, https://www.weforum.org/greatreset/ (last visited Apr. 24, 2021)

78. WHO urges countries to build a fairer, healthier world post-Covid-19, World Health Organization (Apr. 6, 2021), https://www.who.int/news/item/06-042021-who-urges-countries-to-build-a-fairer-healthier-world-post-covid-19

\section{LEGISLATIVE MATERIALS, REPORTS, PRESENTATIONS AND UNPUBLISHED PAPERS}

79. Charles B. Craver, How to Conduct Effective Telephone and E-Mail Negotiations (October 7, 2015)

80. Geraldine Fauville et al., Zoom Exhaustion \& Fatigue Scale (Feb. 15, 2021), https://papers.ssrn.com/sol3/papers.cfm?abstract id=3786329

81. Jonathan Gratch, David DeVault and Gale Lucas, The Benefits of Virtual Humans for Teaching Negotiation at the International Conference on Intelligent Virtual Agents (Sep. 2016)

82. Guidance Note on Possible Measures Aimed at Mitigating the Effects of the Covid-19 Pandemic, International Chamber of Commerce (Apr. 9, 2020), https://iccwbo.org/publication/icc-guidance-note-on-possible-measuresaimed-at-mitigating-the-effects-of-the-covid-19-pandemic/

83. Inspiring National Indigenous Education for Aotearoa New Zealand's Bachelor of Laws Degree (2020)

84. David Allen Larson, ODR Accessibility for Persons with Disabilities: We Must Do Better, in Online Dispute Resolution: Theory and Practice (forthcoming)

85. Andrew Mamo, Against Resolution: Dialogue, Demonstration, and Dispute Resolution, Ohio State Journal on Dispute Resolution (forthcoming)

86. Kendall Thomas, Professor at Columbia Law School, Presentation at the University of Wisconsin Law Review Symposium: Critical Race Theory - Origins, Permutations, and Current Queries (Oct. 22, 2020)

87. UN Convention on International Settlement Agreements Resulting from Mediation (2019)

88. Lisa Waddington and Carly Toepke, Moving Towards Inclusive Education as a Human Right: An analysis of international legal obligations to implement inclusive education in law and policy (2014) 